\title{
Cough Hypersensitivity Syndrome - A Major Advance in the Understanding of Chronic Cough
}

\author{
An Expert Interview with Kian Fan Chung \\ National Heart \& Lung Institute, Imperial College London \& Royal Brompton \& Harefield NHS Trust, London, UK
}

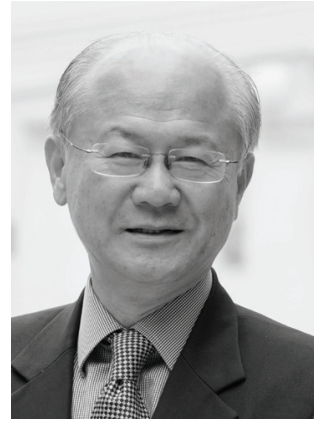

DOl: https://doi.org/10.17925/ERPD.2018.4.1.19

\begin{abstract}
Kian Fan Chung
Kian Fan Chung is Professor of Respiratory Medicine and Head of Experimental Studies Medicine at National Heart \& Lung Institute, Imperial College London, and is Consultant Physician at the Royal Brompton \& Harefield NHS Trust, London. Professor Chung is active in clinical research into asthma and cough, with the aim of improving detection of respiratory disease and discovering and applying new treatments. He is an international authority on the treatment of chronic airway diseases and has published over 600 medical and scientific articles on many aspects of respiratory diseases and respiratory medicine. He has co-edited several books on lung diseases such as Pharmacology and therapeutics of cough (2008); Pharmacology and therapeutics of airways diseases (2010); and Monograph: Severe difficult-to-treat asthma (2011). He serves on the Editorial Boards of many journals including Lancet Respiratory Medicine, Respirology and European Journal of Pharmacology. He is also a Senior Investigator of the National Institute for Health Research. He has lectured extensively in Europe, North America and Asia.
\end{abstract}

\section{Keywords}

Chronic cough, cough hypersensitivity syndrome, diagnosis, treatment

Disclosure: Kian Fan Chung has been renumerated for participation on advisory boards of AstraZeneca, Novartis, Boehringer Ingelheim, GlaxoSmithKline 4D Pharma, Merck Sharp \& Dohme, and Menlo Therapeutics discussing new therapies for respiratory conditions including cough.

Review Process: This is an expert interview and, as such, has not undergone the journal's standard peer review process.

Acknowledgement: Medical writing assistance was provided by Katrina Mountfort of Touch Medica Media and was supported by Touch Medical Media. Authorship: The named author meets the International Committee of Medical Journal Editors (ICMJE) criteria for authorship of this manuscript, takes responsibility for the integrity of the work as a whole, and has given final approval for the version to be published.

Open Access: This article is published under the Creative commons Attribution Non-commercial License, which permits any non-commercial use, distribution, adaptation, and reproduction provided the original author and source are given appropriate credit. (C) The Author 2018 .

Received: 19 July 2018

Published Online: 5 September 2018

Citation: European Respiratory \& Pulmonary Diseases. 2018;4(1):19-20

Corresponding Author: Kian Fan Chung, National Heart and Lung Institute, Imperial College, Dovehouse Street, London SW3 6LY, UK. E: f.chung@imperial.ac.uk

Support: No funding was received in

the publication of this article.
C ough is a common complaint that often necessitates a visit to a primary care provider, ${ }^{1}$ but typically resolves spontaneously within a few weeks. Chronic cough, which is a cough that has lasted for more than 8 weeks, is a more difficult condition to manage and satisfactory control is not achieved in a substantial number of patients. ${ }^{2}$ t has been suggested that many cases of chronic cough may share a common mechanism: that of a hypersensitive cough response. ${ }^{3}$ This has led to the definition of a new disease entity: cough hypersensitivity syndrome (CHS). ${ }^{4-6}$ In an expert interview, Professor Kian Fan Chung of the National Heart \& Lung Institute, Imperial College and the Royal Brompton \& Harefield NHS Trust, London, UK, discusses CHS and the recent advances in our understanding of this condition that is leading to the development of novel treatment approaches.

\section{Q. What is the difference between chronic cough and cough hypersensitivity syndrome?}

Chronic cough is a clinical condition that is defined as cough lasting for at least 8 weeks. ${ }^{2}$ This definition is used to enable clinicians to trigger a series of steps to diagnose any underlying conditions that may be causing the cough, for example a chest X-ray to exclude lung cancer. The patient is then managed according to any associated conditions found according to the set of guidelines set by respiratory societies including the European Respiratory Society (ERS). CHS was defined a few years ago by the ERS as a condition in which the cough is caused by stimuli that don't usually cause cough, or a hypersensitivity to stimuli that are known to be tussive, e.g. citric acid or capsaicin. ${ }^{5}$ While this hypersensitive mechanism has been imputed initially in patients with chronic cough where no cause of the cough has been found, there is now evidence that even in patients with chronic cough associated with conditions such as asthma, chronic obstructive pulmonary disease, pulmonary fibrosis or gastroesophageal reflux disease, this mechanism is underlying the chronic cough. So, patients with CHS may have hypersensitivity to stimuli that do not usually induce coughing e.g. talking, laughing, going outside in cold weather or smelling perfume. Other common complaints are a sensation of having something stuck or irritating in the throat, and difficulty breathing such as a feeling that there is a blockage at the level of the throat and the patient can't get air into the lung. While we don't yet have all the evidence, I believe that most patients presenting with a chronic cough have CHS.

\section{Q. What are the major challenges in the diagnosis and treatment of cough hypersensitivity syndrome?}

The diagnosis is not challenging and can be determined, to a large extent, by asking questions about what induces the cough and whether the cough is sensitive to simple tests, including measuring 
the cough response to inhaling citric acid or capsaicin. Patients with $\mathrm{CHS}$ respond to much lower concentrations of these chemicals than those without $\mathrm{CHS}$. However, we need to find better tests of $\mathrm{CHS}$.

The treatment of CHS, however, remains a challenge - so far there is a lack of good treatments for controlling cough in CHS because we don't understand entirely how this hypersensitivity occurs and the pathways that lead to its cause.

\section{Q. How do you detect cough hypersensitivity syndrome in patients with underlying diseases such as asthma?}

I believe that $\mathrm{CHS}$ can underlie the chronic cough accompanying many chronic pulmonary inflammatory conditions such as asthma. Chronic cough may persist in patients with asthma whose condition is otherwise well controlled by asthma medications, in this case it is likely that the cough is underlined by CHS. One could assess cough hypersensitivity by measuring the response to citric acid or capsaicin, which are tussive agents, but these tests are not widely used, only in specialised cough centres.

\section{Q. What is the role of adenosine triphosphate in cough sensitisation?}

Until recently, we knew little about the role of adenosine triphosphate (ATP). A study in Manchester investigated a compound that blocks the $\mathrm{P} 2 \mathrm{X}_{3}$ receptor - an ATP binding receptor. This drug was successful in suppressing cough in patients with idiopathic chronic cough, particularly in those with a high cough rate measured on a cough monitor, indicating that ATP may be important in cough sensitisation. This also complements previous information that the ATP/P2X ${ }_{3}$ axis may be important in bladder overreactivity or chronic visceral pain. ${ }^{8}$ The role of ATP and the $\mathrm{P}_{2} \mathrm{X}_{3}$ receptor in $\mathrm{CHS}$ however needs to be fully elucidated. Cough is induced by stimulation of nerve endings in the upper airway by an external stimulus that sends a signal through the vagus nerves to various brain centres to cause the process of cough. ATP and its $\mathrm{P} 2 \mathrm{X}_{3}$ receptor may work at any part of this process from the upper airways/lungs to the brain.

\section{Q. What novel pharmacological approaches are in clinical development for cough and cough hypersensitivity syndrome?}

This concept of $\mathrm{CHS}$ is proving useful in allowing researchers to focus on pathways that could be blocked to reduce cough. A P2X receptor antagonist (MK-7264) has now been developed by Merck ${ }^{9}$ and is currently in phase III studies (NCT03449147, NCT03449134). At least two other companies are also working on $\mathrm{P} 2 \mathrm{X}_{3}$ receptor antagonists. A neurokinin-1 receptor antagonist is also being targeted and phase ॥ clinical studies are in progress. ${ }^{10} \mathrm{An}$ agonist of the nicotine receptor will soon be going into an early proof of concept study. This is an area of great promise for novel effective antitussives at the moment and research is progressing very quickly. $\square$
1. Whaley LE, Businger AC, Dempsey PP, et al. Visit complexity, diagnostic uncertainty, and antibiotic prescribing for acute diagnostic uncertainty, and antibiotic prescribing for acute
cough in primary care: a retrospective study. BMC Fam Pract. 2013;14:120.

2. Pavord ID, Chung KF. Management of chronic cough. Lancet. 2008;371:1375-84.

3. MCGarvey LP. Does idiopathic cough exist? Lung. 2008;186 Suppl. 1:S78-81.

4. Chung KF. Chronic 'cough hypersensitivity syndrome': a more precise label for chronic cough. Pulm Pharmacol Ther. 2011;24:267-71.

5. Morice AH, Millqvist E, Belvisi MG, et al. Expert opinion on the cough hypersensitivity syndrome in respiratory medicine. Eur Respir I. 2014:44:1132-48.

6. Chung KF, MCGarvey L, Mazzone SB. Chronic cough as a neuropathic disorder. Lancet Respir Med. 2013;1:414-22

7. Abdulqawi R, Dockry R, Holt K, et al. P2X3 receptor antagonist (AF-219) in refractory chronic cough: a randomised, double-blind, placebo-controlled phase 2 study. Lancet. 2015;385:1198-205.

8. Ford AP, Undem BJ. The therapeutic promise of ATP antagonism at P2X3 receptors in respiratory and urological disorders. Front Cell Neurosci. 2013:7:267.
9. Smith JA, Kitt MM, Morice AH, et al. MK-7264, a P2X3 receptor antagonist, reduces cough frequency in patients with refractory chronic cough: results from a randomized with refractory chronic cough: results from a randomized,
controlled, phase $2 \mathrm{~b}$ clinical trial. Am I Respir Crit Care Med. controlled, phase

10. Smith JA, Allman $D$, Badri $H$, et al. The neurokinin-1 receptor antagonist orvepitant is a novel anti-tussive therapy for chronic refractory cough: results from a phase 2 study (VOLCANO-1). Am I Respir Crit Care Med 2017;195:A2672. 